\title{
Estudo in vitro sobre a efetividade de desinfetantes na limpeza de cones de guta-percha
}

\section{In vitro study on the effectiveness of disinfectants for cleaning gutta-percha cones}

\author{
Djenifer Regina Birck* \\ Daniela Cristina Miyagaki* \\ Daniela Jorge Corralo*** \\ Fabiana Tonial ${ }^{* * * *}$
}

\section{Resumo}

Introdução: para se obter um tratamento endodôntico de sucesso, várias etapas devem ser seguidas. Igualmente, um rigoroso esquema para máxima redução dos microrganismos presentes deve ser seguido bem como para sua não introdução. O material obturador de canais mais utilizado mundialmente, a guta-percha, por não poder ser esterilizada, deve ser desinfetada para que não haja a recontaminação do conduto radicular. Objetivo: avaliar a capacidade biocida de três soluções: hipoclorito de sódio a 5,25\%, clorexidina a $2 \%$ e ácido peracético a $0,2 \%$, em um período de tempo de um minuto, em cones de guta-percha previamente contaminados com Enterococcus faecalis. Materiais e método: foram utilizados oitenta cones, divididos em quatro grupos igualmente $(n=10)$. Em cada grupo, foi utilizada uma solução desinfetante, exceto no grupo um, no qual foi realizada apenas uma lavagem com água destilada estéril. Resultados: os resultados dessa avaliação indicaram que as soluções de ácido peracético e clorexidina foram $100 \%$ eficazes, enquanto que o hipoclorito alcançou 95\% de efetividade. A água destilada foi completamente ineficaz. Conclusão: todos os desinfetantes testados nesta pesquisa foram efetivos na descontaminação rápida de cones de guta-percha.

Palavras-chave: Ácido peracético. Clorexidina. Desinfecção. Guta-percha. Hipoclorito de sódio.

\section{Introdução}

O tratamento do sistema de canais radiculares é um recurso de primordial importância na manutenção de dentes com comprometimento pulpar afe$\operatorname{tados}^{1}$. A manutenção ou a introdução de microrganismos pode acarretar o insucesso do tratamento endodôntico e a consequente perpetuação da doença ${ }^{2}$. A infecção pulpar persistente tem vários motivos, entre eles, a insuficiência de preparo biomecânico, a deficiência no selamento coronal e a contaminação do canal no decorrer do tratamento ou entre sessões ${ }^{3}$.

Para realizar a limpeza e a desinfecção dos canais radiculares são utilizados materiais esterilizados, exceto cimento e cones obturadores. Por serem termossensíveis, cones de guta-percha, os mais utilizados mundialmente como obturadores, não admitem ser esterilizados por meios tradicionais de calor úmido ou seco ${ }^{4}$. Dessa maneira, deve ser realizada a esterilização por meio químico (a qual pode ser realizada de forma gasosa ou líquida) ou a desinfecção (pelos meios físico-líquido ou químico-líquido) ${ }^{5}$.

Os requisitos para o desinfetante ideal são: toxicidade reduzida, ser solúvel, ser estável, possuir grande atividade de destruição de microrganismos, ser solvente orgânico, não apresentar capacidade

Acadêmica de Odontologia da Universidade de Passo Fundo, Passo Fundo, Rio Grande do Sul, Brasil.

Doutora em Endodontia, Faculdade de Odontologia de Piracicaba da Universidade Estadual de Campinas. Professora adjunta I da Faculdade de Odontologia da Universidade de Passo Fundo, Passo Fundo, Rio Grande do Sul, Brasil.

${ }^{* * *}$ Mestre em Clínica Odontológica, Ênfase em Cariologia. Professora adjunta I da Faculdade de Odontologia da Universidade de Passo Fundo, Passo Fundo, Rio Grande do Sul, Brasil.

**** Doutora em Microbiologia, Parasitologia e Patologia. Professora substituta temporária do Instituto de Ciências Biológicas da Universidade de Passo Fundo, Passo Fundo, Rio Grande do Sul, Brasil. 
de corrosão a materiais metálicos, ser efetivo rapidamente, não possuir odor desagradável, entre outros fatores ${ }^{6}$.

De acordo com os fabricantes, os cones obturadores dos canais radiculares são fabricados em condições assépticas e possuem superfície suave, o que desfavorece a colonização bacteriana e apresenta poucas condições para crescimento de microrganismos, como umidade e oferta de nutrientes, além de ter em sua composição o óxido de zinco (que apresenta atividade antisséptica $)^{7}$. Todavia, os fabricantes não garantem condição asséptica do material e, além disso, a exposição aos aerossóis do ambiente odontológico, o manuseio durante a obturação endodôntica e as condições de armazenagem podem permitir a colonização por microrganismos nas referidas superfícies ${ }^{2,8}$.

Dentre as substâncias utilizadas estão hipoclorito, utilizado na irrigação endodôntica, clorexidina, utilizado da mesma forma que o hipoclorito, e ácido peracético, utilizado na desinfecção e esterilização de superfícies contaminadas, entre outros euipamentos ${ }^{9}$.

$\mathrm{O}$ presente estudo teve como objetivo avaliar a eficácia do digluconato de clorexidina em gel $2 \%$, hipoclorito de sódio $5,25 \%$ e ácido peracético $0,2 \%$ no combate ao Enterococus faecalis, comparar essas substâncias e propor um protocolo de desinfecção rápido e eficiente para desinfecção de cones de guta-percha.

\section{Materiais e método}

Os cones incluídos no estudo foram adquiridos em dentárias em embalagens lacradas, contendo 120 unidades, de calibre \#15, da marca Tanari (Manacapuru, Amazonas, Brasil). Dos 120 cones da embalagem, foram utilizados oitenta.

Assim, foram preparados oitenta tubos de ensaio com cerca de $3 \mathrm{~mL}$ de caldo Brain Heart Infusion (BHI). O experimento foi realizado em capela de fluxo laminar. Com o auxílio de pinças esterilizadas, 120 cones foram removidos da embalagem original e imersos em uma suspensão de Enterococcus faecalis (NEWP0012), sendo contaminados durante 5 minutos. Após o período de contaminação, os cones foram removidos da suspensão com o auxílio de nova pinça estéril e lavados em água destilada esterilizada.

As amostras foram divididas, aleatoriamente, em quatro grupos $(\mathrm{n}=10)$. Grupo controle (G1), clorexidina gel $2 \%$ (G2), ácido peracético $0,2 \%$ (G3) e hipoclorito de sódio 5,25\% (G4). Para todos os grupos, o procedimento foi realizado de maneira similar. Com o auxílio de pinças esterilizadas, todos os cones de cada grupo foram imersos nas respectivas soluções pelo período de 1 minuto.

Após o tempo de contato com as soluções, os cones foram removidos dos respectivos agentes desinfetantes com pinças estéreis, imersos em recipiente novo com água destilada esterilizada e imersos individualmente em tubos de ensaio com caldo BHI, após foram devidamente rotulados. Os tubos foram fechados com tampa própria, e armazenados em estufa bacteriológica a $36,5^{\circ} \mathrm{C}$ durante 72 horas, intervalo no qual foram realizadas leituras, pelo mesmo observador, em 24, 48 e 72 horas, com observação visual de turvação do meio.

\section{Resultados}

Os resultados obtidos após o período de incubação das amostras estão apresentados no Quadro 1.

Quadro 1 - Resultados

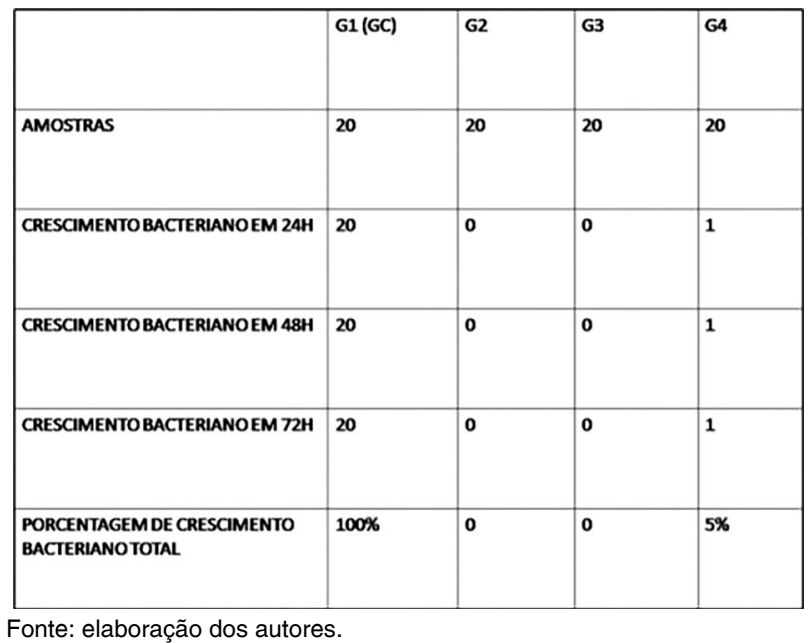

As soluções desinfetantes a base de ácido peracético a $2 \%$ e o gel de clorexidina $2 \%$ demonstraram efetividade satisfatória, eliminando todas as bactérias presentes nos cones. Por sua vez, a solução de hipoclorito de sódio a 5,25\% demonstrou atividade antimicrobiana na grande maioria dos cones. Contudo, como houve crescimento bacteriano em um dos vinte cones desinfetados com essa substância, o resultado foi de $95 \%$ de eficácia de descontaminação. O grupo controle não apresentou atividade antimicrobiana, demostrando o desenvolvimento de bactérias em todas as amostras após 24 horas de incubação.

\section{Discussão}

A endodontia é a especialidade da odontologia que se atém ao estudo da anatomia, da fisiologia e de patologias da polpa dentária bem como do tratamento das doenças que acometem esse componente do órgão dental ${ }^{10}$. Para essa ciência, é observada uma interdependência entre doença e microrganismos, sendo que a permanência ou a reintrodução deles é considerada o principal fator de insucesso endodôntico, o que é diagnosticado de acordo com o surgimento ou a progressão de lesão periapical ${ }^{2,10-13}$.

Para que não se comprometa a cadeia asséptica do tratamento endodôntico, todas as fases devem 
ser realizadas com materiais preferencialmente esterilizados e, em associação, deve-se realizar uma adequada desinfecção e modelagem dos canais com soluções próprias para esse fim ${ }^{6,13-15}$.

Antes do uso dos cones de guta-percha, indica-se a desinfecção desses materiais, uma vez que podem estar contaminados na embalagem ${ }^{12}$ ou contaminar-se durante manuseio ou por aerossóis da clínica odontológica $^{1,2,4,6,16-24}$.

Os resultados do ácido peracético, de maneira biocida, são positivos contra Clostridium perfingens e Escherichia coli ${ }^{25}$; contra Escherichia coli e Salmonella ${ }^{26}$; contra Staphylococcus aureus meticilina-resistente ${ }^{27}$; contra colônias de bactérias coletadas em equipos da clínica-escola do Departamento de Odontologia da Universidade Estadual da Paraíba; contra C. albicans ${ }^{28,29}$; na desinfecção de esgoto sanitário ${ }^{30}$; contra Candida albicans e Bacillus subtilis $^{31}$; contra Streptococcus viridans ${ }^{32}$.

O ácido peracético atua como desinfetante de superfícies fixas e tem a capacidade de desnaturar as proteínas, o que ocasiona uma permeabilidade da parede celular e, dessa forma, oxida as ligações sulfidril e sulfúricas das proteínas e enzimas. Age rapidamente sobre a microbiota, inclusive contra esporos bacterianos, e pode ser utilizado em concentrações baixas, de 0,001 a 0,2\%, além de apresentar efetividade em contato com matéria orgânica ${ }^{33}$.

Outro desinfetante muito utilizado na terapia endodôntica é o digluconato de clorexidina. Estudos anteriores verificaram que clorexidina a $2 \%$ foi bactericida de 1 a 5 minutos e esporicida em 15 minutos $^{34}$, soluções aquosas de clorexidina a partir de $1 \%$ foram eficazes contra cepas de Streptococcus mutans, Staphylococcus aureus, Pseudomonas aeruginosa, Candida albicans e Klebsiella pneumoniae, em diversas superfícies diferentes ${ }^{35}$; a clorexidina a $4 \%$ foi efetiva contra $E$. faecalis ${ }^{36}$; clorexidina a $2 \%$ foi eficaz, em 5 minutos, contra $S$. aureus, $E$. faecalis e C. albicans, e esporos de Bacillus subtilis ${ }^{17}$; clorexidina $4 \%$ foi eficaz contra $E$. faecalis em 30 segundos ${ }^{4}$; a clorexidina $0,1 \%$ foi eficaz na descontaminação do sistema de água odontológica.

A ação biocida da clorexidina ocorre em um grande número de bactérias Gram positivas e negativas, aeróbias e anaeróbias, agindo como bactericida ou bacteriostático. A ação bacteriostática acontece quando a síntese de ATP das bactérias é inibida, o que ocorre quando a solução de clorexidina é utilizada em baixas concentrações. Já a ação bactericida se dá pela ruptura da membrana citoplasmática das bactérias, o que ocorre quando a solução encontra-se em concentrações elevadas ${ }^{37}$. Contudo, outros estudos indicam que a clorexidina $2 \%$ não foi efetiva para eliminar microrganismos dos cones de guta-percha, mesmo após 72 horas de contato ${ }^{1,6,38}$.

O terceiro desinfetante utilizado, o hipoclorito, que apresentou crescimento bacteriano no presente estudo, obteve $95 \%$ de efetividade. Os trabalhos realizados anteriormente demonstraram que o hi- poclorito foi efetivo ${ }^{1,24,34,36,38,39}$. Alguns estudos não encontraram diferenças na descontaminação entre o hipoclorito e a clorexidina ${ }^{4,23,40}$. Entretanto, pesquisas determinaram que o hipoclorito de sódio ocasionou alterações importantes na composição dos cones descontaminados em qualquer das concentrações utilizadas, como mudanças na superfície e presença de cristais de hipoclorito ${ }^{2,13,14}$.

O hipoclorito possui as características de bactericida, virucida, fungicida, tuberculicida e esporicida, de acordo com a concentração utilizada ${ }^{41}$. O exato mecanismo ainda não está elucidado. Contudo, autores defendem que a ação biocida é dependente da concentração de ácido hipocloroso não dissociado em solução. Esse ácido apresenta um efeito germicida, oxidando os grupos sulfidril das enzimas bacterianas, sem as quais são interrompidas as reações do metabolismo, o que resulta em morte celular ${ }^{42}$.

Mais pesquisas devem ser realizadas a fim de elucidar o tempo e as concentrações mais indicadas para cada solução desinfetante.

\section{Conclusão}

De acordo com os dados obtidos nesta pesquisa, pode-se concluir que clorexidina gel $2 \%$, ácido peracético $0,2 \%$ e hipoclorito de sódio $5,25 \%$ são soluções efetivas para descontaminação de cones de guta-percha infectados com Enterococcus faecalis após o período de 1 minuto de contato.

\section{Abstract}

Introduction: For a successful endodontic treatment, many steps should be followed, and similarly, there should be a strict scheme for maximum reduction of microorganisms present, as well as for preventing their reintroduction. The canal filler material mostly used worl$d$ wide is gutta-percha, and since it may not be sterilized, it should be disinfected to prevent the recontamination of root canal. Objective: This study proposed to assess the biocidal capacity of three solutions: $5.25 \%$ sodium hypochlorite, $2 \%$ chlorhexidine, and $2 \%$ peracetic acid, in a period of one minute, against gutta-percha cones previously contaminated with Enterococcus faecalis. Method: Eighty cones were used, divided into 4 groups equally ( $n=10)$. A disinfectant solution was used for each group except for group one, which was washed only once with sterile distilled water. Results: The results of this assessment indicated that solutions of peracetic acid and chlorhexidine were $100 \%$ effective, while hypochlorite achieved $95 \%$ of effectiveness. Distilled water was completely ineffective. Conclusion: It was concluded that all disinfectant solutions tested in this research were effective on the decontamination of gutta-percha cones.

Keywords: Peracetic acid. Chlorhexidine. Disinfection. Gutta-percha. Sodium hypochlorite. 


\section{Referências}

1. Amaral G, Carraz R, Freitas LF, Fidel SR, Castro AJR. Efetividade de três soluções na descontaminação de cones de guta-percha e de Resilon. Rev Bras Odontol 2013; 70(1):54-8.

2. Carvalho AS, Leal FM, Vasconcelos RA, Junqueira RB, Gonçalves SHF. EDS analysis of gutta-percha cones disinfected by $1 \%$ and $2,5 \%$ sodium hipochlorite solutions. Braz Dent Sci $2015 ; 18(4): 84-8$

3. Sahli CC, Aguadé EB. Endodoncia: técnicas clínicas y bases científicas. 2. ed. Barcelona: Masson; 2006. [citado 2016 mar. 25]. Disponível em URL: https://books.google.com.br/books?id $=9 \mathrm{RD} 1 \mathrm{udT} 0 \mathrm{iwAC} \&$ printsec $=$ frontcover $\& \mathrm{dq}=$ endodontia + sahl i\&hl=es\&sa=X\&ved=0ahUKEwiJ8vG67dzLAhWIFpAKHX8s BXgQ6AEIJjAA\#v=onepage \&q=endodontia\%20sahli\&f=false.

4. Gomes CC, Camões ICG, Freitas LF, Pinto SS, Saraiva SM, Sambati S. Avaliação do hipoclorito de sódio e da clorexidina na desinfecção de cones de guta percha. Rev Odontol Univ Cid São Paulo 2010; 22(2):94-103.

5. Processamento de Artigos e Superfícies em Estabelecimentos de Saúde. Brasília: Ministério da Saúde; 1994. [citado 2016 mar. 25]. Disponível em URL: http://www.anvisa.gov. br/servicosaude/controle/processamento_artigos.pdf.

6. Pinheiro GR. Análise comparativa da eficiência dos agentes químicos na desinfecção e esterilização dos cones de guta-percha - estudo in vitro [Monografia de Graduação]. Campina Grande: Faculdade de Odontologia, Universidade Estadual da Paraíba; 2011.

7. Pereira OLS, Siqueira JF. Contamination of gutta-percha and resilon cones taken directly from the manufacturer. Clin Oral Invest 2010; 14(3):327-30

8. Topuz O, Saglam BC, Sen F, Sen S, Gokagaç G, Gorgul G. Effects of sodium hypochlorite on gutta-percha and Resilon cones: an atomic force microscopy and scanning electron microscopy study. Oral Surg Oral Med Oral Pathol Oral Radiol Endod 2011; 112(4):e21-e6.

9. Subba N, Prabhakar V, Koshy M, Abinaya K, Prabu M, Thangavelu L. Efficacy of peracetic acid in rapid disinfection of resilon and gutta-percha cones compared with sodium hypochlorite, clorexidine, and povidone-iodine. J Endod 2013; 39(10):1261-4.

10. European Society Of Endodontology. Quality guidelines for endodontic treatment: consensus report of the European Society of Endodontology. Int Endod J 2006; 39(12):921-30.

11. Pinheiro ET. Investigação de bactérias associadas ao insucesso do tratamento endodôntico [Dissertação de Mestrado]. Piracicaba: Faculdade de Odontologia de Piracicaba, Universidade Estadual de Campinas; 2000.

12. Siqueira Júnior JF, Rôças IN. Microbiologia endodôntica. In: Torabinejad M, Walton RE. Endodontia - princípios e prática. Rio de Janeiro: Elsevier; 2010.

13. Maros IN. Avaliação da desinfecção de cones de guta-percha utilizando hipoclorito de sódio e clorexidina [Monografia de Especialização]. Manaus: ICS Soebras, Funorte; 2014.

14. Brito SMSM. Análise morfológica da superfície dos cones de guta-percha submetidos à desinfecção com hipoclorito de sódio a $1 \%$ e a $2,5 \%$ e sua influência no selamento marginal da obturação [Dissertação de Mestrado]. São José dos Campos: Faculdade de Odontologia de São José dos Campos, Universidade Estadual Paulista; 2007.

15. Rosa PCF. Análise morfológica de cones de guta-percha submetidos a diferentes tratamentos de desinfecção e sua influência na microinfiltração [Dissertação de Mestrado]. São José dos Campos: Faculdade de Odontologia de São José dos Campos, Universidade Estadual Paulista; 2011.
16. Nacif MCAM. Análise da contaminação microbiana de cones de guta-percha em uso clínico e de cones de papel absorvente [Dissertação de Mestrado]. Rio de Janeiro: Faculdade de Odontologia, Universidade Estácio de Sá; 2010.

17. Redmerski R, Bulla JR, Moreno T, Garcial LB, Cardoso CL. Disinfection of gutta-percha cones with chlorexidine. Braz J Microbiol 2007; 38(4):649-55

18. Pereira OLS. Avaliação da contaminação de cones de guta percha e Resilon utilizados no tratamento endodôntico [Dissertação de Mestrado]. Rio de Janeiro: Faculdade de Odontologia, Universidade Estácio de Sá; 2008.

19. Silva EM, Sponchiado Junior EC, Marques AAF. Microbiological assessment of contamination of gutta-percha cones used by post-graduation students. J Health Sci Inst 2010; 28(3):235-6.

20. Prado M, Assis DF, Gomes BPFA, Simao RA. Effect of disinfectant solutions on the surface free energy and wettability of filling material. J Endod 2011; 37(7):980-2.

21. Sahinkesen G, Oktay EA, Kiliç A. Evaluation of residual antimicrobial effects and surface changes of gutta-percha disinfected of different solutions. J Contemp Dent Pract 2011; $12(1): 47-51$.

22. Salvia ACRD, Teodoro GR, Balducci I, Koga-Ito Y, Oliveira SHG. Effectiveness of $2 \%$ peracetic acid for the disinfection of gutta-percha cones. Braz Oral Res 2011; 25(1):23-7.

23. Rocha EALSS, Limeira FIR, Carvalho AVOR, Santos KSA, Medeiros ACD. Avaliação da eficácia de diversas substâncias químicas na descontaminação de cones de guta-percha. Odontol Clín Cient 2013; 12(1):35-8.

24. Schmidt MHM, Sallenave RF, Demarchi A, Farina AP, Cecchin D, Souza MA. Effectiveness of different auxiliary chemical substances in the rapid disinfection of gutta-percha points - an in vitro study. RFO UPF 2015; 20(1):64-8.

25. Souza JB, Daniel LA. Comparação entre hipoclorito de sódio e ácido peracético na inativação de $E$. coli, colifagos e $C$. perfringens em água com elevada concentração de matéria orgânica. Eng Sanit Ambient 2005; 10(2):111-7.

26. Srebernich SM. Utilização do dióxido de cloro e do ácido peracético como substitutos do hipoclorito de sódio na sanitização do cheiro-verde minimamente processado. Ciên Tecnol Aliment 2007; 27(4):744-50.

27. Svidzinski AE, Posseto I, Padua RAF, Tavares TR, Svidzinski TIE. Eficiência do ácido peracético no controle de Staphylococcus aureus meticilina resistente. Cien Cuid Saúde 2007; 6(3):312-8

28. Regis DLBP. Estudo comparativo in vitro entre o ácido peracético e o glutaraldeído na desinfecção de ambientes odontológico [Monografia de Graduação]. Campina Grande: Faculdade de Odontologia, Universidade Estadual da Paraíba; 2011.

29. Stopiglia CDO, Carissimi M, Scroferneker ML, Fortes CBB. Microbiological evaluation of peracetic acid for disinfection of acrylic resins. Rev Odonto Ciênc 2011; 23(3):238-41.

30. Cavallini GS, Campos SX, Souza JB, Vidal CMS. Utilização do ácido peracético na desinfecção de esgoto sanitário: uma revisão. Semin Ciênc Exatas Tecnol 2012; 33(1):27-40.

31. Reis L, Zanetti AL, Castro Junior OV, Martinez EF. Use of $0.25 \%$ and $0.025 \%$ peracetic acid as disinfectant agent for chemically activated acrylic resin: an in vitro study. Rev Gaúcha Odontol 2012; 60(3):315-20.

32. Carrara D, Shirahige CA, Braga ACPV, Ishioka S, Sakai $\mathrm{P}$, Takeiti $\mathrm{MH}$, et al. A desinfecção de endoscópios com ácido peracético por dez minutos é efetiva? Rev Sobrec 2013; 18(4):38-46. 
33. Brasil. Agência Nacional de Vigilância Sanitária. Segurança do paciente em serviços de saúde: limpeza e desinfecção de superfícies. Brasília: Anvisa; 2010.

34. Cardoso CL, Redmerski R, Bittencourt NLR, Kotaka CR. Effectiveness of different chemical agents in rapid decontamination of gutta-percha cones. Braz J Microbiol 2000; 31(1):72-5.

35. Bambace AMJ, Barros EJA, Santos SSF, Jorge AOC. Eficácia de soluções aquosas de clorexidina para desinfecção de superfícies. Rev Biociênc 2003; 9(2):73-81.

36. Fagundes FS, Leonardi DP, Haragushiku GA, Barato Filho F, Tomazinho LF, Tomazinho PH. Eficiência de diferentes soluções na descontaminação de cones de guta-percha expostos ao Enterococcus faecalis. Rev Sul-Bras Odontol 2005; 2(2):7-11.

37. Michelotto ALC, Andrade BM, Silva Junior JA, Sydney GB. Clorexidina na terapia endodôntica. RSBO 2008; 5(1):77-89.

38. Gomes BPFA, Vianna ME, Matsumoto CU, Rossi VPS, Zaia AA, Ferraz CR, et al. Disinfection of gutta-percha cones with chlorhexidine and sodium hypochlorite. Oral Surg Oral Med Oral Pathol Oral Radiol Endod 2005; 100(4):512-27.

39. Shnaydman M. Decontamination of endodontic gutta-percha: an in-vitro study [Tese de Mestrado]. Connecticut: University of Connecticut; 2011.

40. Rebollo MLL, Aguillar MG, Rosenblum DSG. Estudio Comparativo del Gluconato de Clorhexidina e Hipoclorito de Sodio: una alternativa en la Desinfección de Conos de Guta percha. Endodoncia Actual 2006; 1(3):8-10.

41. Ferreira DMAO, Leal NMS, Costa CLS. Desinfecção do sistema de água de equipamentos odontológicos com clorexidina. ConScientiae Saúde 2014; 13(3):436-42.

42. Vianna ME, Gomes BPFA, Berber VB, Zaia AA, Ferraz CC, Souza-Filho FJ. In vitro evaluation of the antimicrobial activity of chlorhexidine and sodium hypoclorite. Oral Surg Oral Med Oral Pathol Oral Radiol Endod 2004; 97(1):79-84.

\section{Endereço para correspondência:}

Djenifer Regina Birck

Rua Guarani, 869, Vila Carmem

99072020 Passo Fundo, RS Brasil

Telefone: (46) 99140-4010

E-mail: djenirb@gmail.com

Recebido: 13/06/2016. Aceito: 13/09/2016. 